\title{
Hacia la Consolidación de Palobra
}

Llegamos a la edición número 9 de la revista PALOBRA y con ello se plantean nuevos desafíos los que se dirigen hacia su indexación, así como a la continuidad en el proceso de calidad que desde siempre ha orientado su comité editorial. La revista es reflejo del esfuerzo mancomunado de docentes, estudiantes y grupos de investigación de la Facultad de Ciencias Sociales y Educación, y en su novena edición registra un significativo número de artículos de autores de diferentes universidades del país y del exterior, pero sobre todo de autores de la Universidad de Cartagena, que dan cuenta de análisis múltiples y diversos acerca de la realidad local desde la mirada de las ciencias sociales, humanas y de la educación.

En esta edición se incluyen trabajos resultantes de investigaciones, ensayos, documentos de trabajo y otros, que abordan el tema de lo social en sus diferentes manifestaciones. Es de destacar el énfasis en artículos derivados de investigaciones científicas que dan cuenta de análisis y comprensiones más complejas del contexto social, en especial de la región caribe y la ciudad de Cartagena.

En Los programas de microempresas, una mirada desde las necesidades prácticas y estratégicas de género, la autora Mercedes Rodríguez López hace una reflexión acerca de los programas dirigidos a mujeres de bajos ingresos, desde el concepto de necesidades prácticas y estratégicas de género, como elemento de análisis para la revisión de la planificación de dichos programas y su práctica, contribuyendo además a identificar limitaciones de los enfoques desde los cuales se han sustentado las políticas sociales que apuntan al tema de mujer y género en el desarrollo.

En el ensayo Relaciones de género en investigaciones basadas en experiencias de historia oral, la autora Olga Cabrera García analiza algunas cuestiones acerca de la perspectiva multidisciplinar en la metodología de la historia oral, concentrándose en la entrevista y la construcción del documento oral, como características que le dan su especificidad, para lo cual presenta algunas experiencias particulares. Estudia la vida cotidiana así como la memoria, vinculadas al tiempo, con el propósito de comprender realidades específicas a través de la historia oral.

En el artículo La desigualdad social: Desarrollo y desafíos del Trabajo Social desde la Reconceptualización en América Latina, los trabajadores sociales Norberto Alayón y María Lorena Molina, presentan una síntesis de la ponencia presentada al 33 Congreso Mundial de Escuelas de Trabajo Social-Chile 2006, que aspira

Palobrano. 9 Agosto/2008 
responder a la pregunta: ¿Cuáles son las principales rupturas que se gestan en el Movimiento de Reconceptualización del Trabajo Social y cuáles los principales ejes de debates que influencian la formación profesional? Planteándose lo que implica asumir la comprensión de las "problemáticas sociales" o trascender hacia las "manifestaciones de la cuestión social", de cara a la relación entre la política social y los derechos humanos y la ciudadanía, a fin de contribuir a superar la comprensión de meros instrumentos de control, mecanismos redistributivos y de estímulo al consumo hacia la conquista, ampliación y exigibilidad de derechos sociales. Lo anterior es vinculado con el debate teórico-metodológico-ético político actual en el Trabajo Social en la contemporaneidad Latinoamericana.

Individualidad y Solidaridad. Discursos sobre autonomía en la educación en Trabajo Social. El caso de la Universidad de Cartagena es un artículo donde su autora Liliana Pérez Mendoza presenta resultados parciales de la investigación "Cuando la Autonomía está más allá del Individuo Mismo. A Propósito del Develamiento de los Discursos sobre Autonomía en la Educación en Trabajo Social", realizada en el año 2005 y que toma como caso la educación en Trabajo Social de la Universidad de Cartagena. Para ello son analizados los discursos que sobre autonomía expresaron docentes, estudiantes y directivos de esta unidad académica, quienes participaron en la implementación del plan de estudios de Trabajo Social de 1992, a la luz de la constelación conceptual de autonomía como competencia comunicativa, derivada de la perspectiva de la ética discursiva y la teoría de la acción comunicativa de Habermas.

Luego en el articulo, ¿De vagos a ciudadanos o de ciudadanos a vagos? Educación, ciudadanía y exclusión en la provincia de Cartagena, 1903-1920, el historiador Rafael Acevedo Puello, indaga acerca de los proyectos de ciudadanía y de no ciudadanos socializados en los códigos de instrucción pública y de policía en la Provincia de Cartagena, durante el periodo comprendido entre 1903-1930, pretendiendo señalar los mecanismos formales e informales que, asociados a las escuelas y a las celebraciones patrias, hicieron posible la definición del ciudadano como un sujeto político, con connotaciones católicas y productivas para su patria.

El autor, Javier Hernández García en su articulo Formas y modos del trabajo en la hacienda tradicional montemariana (1930-1960), explicita aspectos específicos del ordenamiento social de la hacienda tradicional montemariana en la primera parte del siglo XX (1930-1960), en lo referido a las relaciones de control, sujeción, subalternidad, confrontación, alianza, exclusión, asociadas 
a las formas del trabajo campesino, de acuerdo a como fueron descritas y significadas por los propios actores. Se reelaboran los principales hallazgos del proceso de organización e interpretación de información testimonial que hizo parte del informe de investigación "Aspectos de la Vida Cotidiana en la Hacienda Tradicional en Épocas de Auge y de Crisis en Montes de María (Sucre) 1930$1960 "$.

El profesor Sergio Solano De Las Aguas en Imprentas, tipógrafos y estilos de vida en el caribe colombiano, 1850-1930 analiza la importancia del oficio de la tipografía en el contexto de la República, y su papel en determinar un estilo de vida organizado en torno al honor, la dignidad, la valoración de la educación y del trabajo. Además se discute como ese estilo de vida era compartido por otros sectores laborales, llegando a proponer la tesis de la existencia de unas capas medias de los oficios rudos organizada en torno a un estilo de vida que giraba alrededor de la dignidad personal y familiar.

En Los wayúu, la tierra y la política del carbón en la guajira. 1980-2000: Una visión desde la historia para reparar y no repetir, los historiadores Judith Montero de Daza y Luis Mestra Narváez señalan que la autoconcepción y principio de los Wayúu como "hijos de la tierra" y dueños únicos de todo cuanto existe sobre el suelo y el subsuelo guajiro, no se tuvo en cuenta cuando en los años 80 se inició la explotación del carbón. De esta manera, el Cerrejón y los nativos iniciaron un proceso de negociación donde la Tierra fue el eje fundamental y a la vez punto de choque por su carácter ancestral o su valor como un bien comercial. Este proceso arrojó resultados heterogéneos para la Comunidad, debido a que ésta no negoció como un conjunto, sino que cada clan asumió su defensa y traslado a través de sus propios líderes, mientras que otros en cambio, optaron por el uso de mecanismos legales disponibles en la ley colombiana para defender sus derechos, cobrando fuerza la militancia política a través de organizaciones como el Yanama.

El autor Camilo Rey Sabogal en Aproximaciones teóricas y empíricas a la relación de causalidad entre desigualdad y crecimiento: Un análisis para Colombia 19852006, examina las posibles relaciones de causalidad entre desigualdad y crecimiento, describiendo los hallazgos de Simón Kuznets que le permitieron formular su Hipótesis de la curva U-Invertida, así como los principales enfoques teóricos y empíricos que se generaron a partir de dicha Hipótesis, a nivel internacional y nacional. Luego, al analizar las cifras del país se encontró que el mecanismo de crecimiento actual se fundamenta en la promoción de la desigualdad. Finalmente, 
el análisis econométrico de las posibles relaciones, permitió extraer los siguientes hallazgos: El alto desempleo y la caída de los salarios reales determina la alta inequidad, la hipótesis de Kuznets se queda corta ante los nuevos hechos que han elevado nuevamente la desigualdad, y que además existe evidencia de que la relación de causalidad va desde distribución hacia crecimiento y no al revés.

En Violencia de género en Cartagena: Crónicas e imágenes del amor que se devela, la profesora Hortensia Naizara Rodríguez basada en los resultados del proyecto de investigación titulado: "Estudio de Caso de la Pareja Homicida en Cartagena de Indias. Un Análisis de Género", muestra que los códigos culturales y valorativos de las masculinidades en conflicto socializadas por los cartageneros conllevan a actos brutales, de irracionalidad y violencia que terminan con la vida de la pareja y vulneran los derechos de los niños, niñas y mujeres. Concluye cómo en los últimos años en Cartagena el amor, la muerte y la violencia se articulan a través de discursos que legitiman la muerte.

En el documento Ética y Trabajo Social: Una aproximación a los debates contemporáneos a partir de un estado del arte la trabajadora social Liz Londoño Piñeros, presenta un estado del arte, realizado como una primera aproximación frente al tema de los debates sobre la ética que hoy circulan en la literatura científica de Trabajo Social.

En esta edición se publica nuevamente el artículo Trabajo Social intercultural: Algunas reflexiones a propósito de la intervención con una comunidad indígena del trapecio amazónico colombiano de la trabajadora social Ruby León Díaz, el cual hizo parte de la revista $N^{0} 8$, debido a que en la misma no se registraron las citas y notas de pie de página.

En Notas de Aquí . . .las estudiantes de Trabajo Social Mary Berrio Berrio e Indira Joly Geliz presentan un ensayo titulado Hacia un cambio en los procesos de acción social colombianos, donde señalan que los actuales procesos de acción social en Colombia se perfilan como una oleada de voluntariado y solidaridad, que no son suficientes para dar respuesta a la cuestión social contemporánea de Colombia, pues no están pensados para hacer frente a los problemas sociales que encierra la cotidianidad colombiana desde los aspectos característicos de las sociedades individualistas del presente, en donde las relaciones se encuentran permeadas por el mercado y las ordenanzas que surgen de las fluctuaciones del capital.

También en Notas de aquí...y Notas de Allá se presentan los eventos y trabajos 
donde han participado docentes y estudiantes, así como los convenios de cooperación firmados por la Universidad de Cartagena y en los cuales la Facultad de Ciencias Sociales y Educación ha participado.

Aprovechamos la oportunidad para renovar la invitación a docentes, estudiantes e investigadores de la ciudad, la región y el país a enviar sus artículos y ensayos para nuestra próxima edición, que será un número especial con motivo de los 10 años de circulación de la revista.

\section{La Editora}

